\title{
Education for sustainable development: the challenge of trans-disciplinarity
}

\author{
Jeffrey I. Steinfeld · Takashi Mino
}

Received: 3 February 2009/Published online: 13 March 2009

(C) Integrated Research System for Sustainability Science and Springer 2009

'Sustainability Science' is an emerging discipline that seeks to understand the interactions within and between global, social, and human systems, the complex mechanisms that lead to the degradation of these systems, and the concomitant risks to human well-being and security. It also seeks to provide the vision and methodology that will lead to the restoration of these systems.

A particular challenge is how to transform the educational system and process to make this possible. The goal of sustainability education (Education for Sustainable Development, ESD) is to equip the younger generation with leadership skills, management capabilities, and the broad knowledge needed to create the new systems that can lead to global sustainability. Recognizing the critical importance of ESD in the quest for sustainability, the Editors of Sustainability Science have invited contributions to this Special Feature Issue from several educational institutions which are leading the way in ESD. We invite and encourage those engaged in ESD to prepare and submit articles for future issues which delineate how the emerging intellectual discipline of Sustainability Science is having a transformative impact on curricula and education, and we look forward to ESD being a regular topic area in this journal.

\section{J. I. Steinfeld ( $\square)$}

Department of Chemistry,

Massachusetts Institute of Technology,

Cambridge, MA 02139, USA

e-mail: jisteinf@mit.edu

T. Mino

Graduate School of Frontier Sciences,

The University of Tokyo,

5-1-5 Kashiwanoha, Kashiwa 277-8563, Japan
The articles in this Special Feature Issue deal with a wide range of ESD initiatives taking place in universities around the world. In Japan, the Integrated Research System for Sustainability Science (IR3S), of which Sustainability Science is the official journal, is a multi-university research and education initiative. Uwasu et al. describe the new Masters level educational program of the Research Institute for Sustainability Science, which is the implementation of IR3S at Osaka University. Onuki and Mino provide a report on the purposes and structure of the Graduate Program in Sustainability Science recently established at the University of Tokyo.

In the United States, the Center for Sustainable Engineering (a consortium of Arizona State University, the University of Texas at Austin, and Carnegie Mellon University in Pittsburgh) has been conducting a survey and analysis of the sustainability content of engineering school curricula. Allenby et al. present initial findings from this survey. The Graham Environmental Sustainability Institute (GESI) was established at the University of Michigan in 2006 to promote educational initiatives related to environmental sustainability. Wright et al. describe an interdisciplinary educational collaboration between GESI and the University of Concepción (Chile) focused on water and hydropower resources in Chile. And at the Massachusetts Institute of Technology (MIT), a project-based course called Terrascope challenges first-year undergraduate students to find solutions to large-scale problems and to communicate their findings to a wide variety of audiences. The article by Epstein et al. gives an account of the Terrascope program.

In Europe, the advancement of sustainability education is taking place within the framework of the Bologna process, which seeks to harmonize higher education activities among the EU members. A team of authors from three 
universities which have been among the leaders in ESD (Polytechnic University of Catalunya, Spain; Delft University of Technology, Netherlands; and Chalmers University of Technology, Sweden) describe their progress in bringing ESD into the Bachelors level programs at these universities.

The articles in this special feature issue have several important commonalities. Since many of these initiatives have been established only recently, it has not always been possible to offer an in-depth assessment of the successes (or lack thereof) for a particular approach. These articles should, therefore, be viewed as 'case reports' on ESD initiatives underway which, we hope, will suggest and stimulate additional initiatives at other universities. There is a clear common theme to all of these initiatives, though, and that is the inter- or trans-disciplinary nature of the programs and curricula being developed and implemented. As Yoshikawa (2008) has noted, this aspect, which he terms 'synthesiology,' is a core element of sustainability science. Wilson (1998) has similarly designated 'consilience,' defined as the unity of knowledge, or the synthesis of knowledge from different specialized fields of human endeavor, as being essential for addressing the problems that face human society and the natural environment. Professor Akito Arima's message, "A Plea for More Education for Sustainable Development," clearly states both the need for and the difficulties associated with this approach.
The articles in this Special Feature Issue highlight some of the many strategies that are being developed to introduce these principles into higher education. If these efforts succeed, we may be at the threshold of a paradigm shift in our educational systems, which could be as far-reaching and momentous as the transition which took place in the 15th-16th centuries, from the medieval scholastic system to the empirical, discipline-based educational model which still forms the basis of our universities. This model has served us very well in the past, leading to enormous expansions of human knowledge, technology, and the global economy, but it may not be sufficient to address the problems of global sustainability that we now face, which result, in part, from this growth in human activity. Indeed, this transition must succeed if we are to leave a healthy environment, a just society, and a sustainable future to our descendants.

\section{References}

Wilson EO (1998) Consilience: the unity of knowledge. Alfred A. Knopf/Random House, New York

Yoshikawa H (2008) Synthesiology as sustainability science. Sustain Sci 3(2):169-170 